\title{
Effect of Nanosilica Filled Polyurethane Composite Coating on Polypropylene Substrate
}

\author{
Yern Chee Ching and Nurehan Syamimie \\ Department of Mechanical Engineering, Faculty of Engineering, University of Malaya, Lembah Pantai, 50603 Kuala Lumpur, Malaysia \\ Correspondence should be addressed to Yern Chee Ching; chingyc@um.edu.my
}

Received 19 July 2013; Revised 16 September 2013; Accepted 20 September 2013

Academic Editor: Mengnan Qu

Copyright ( 2013 Y. C. Ching and N. Syamimie. This is an open access article distributed under the Creative Commons Attribution License, which permits unrestricted use, distribution, and reproduction in any medium, provided the original work is properly cited.

\begin{abstract}
Acrylic based polyurethane (PU) coatings with various amounts of nanosilica contents were prepared using solution casting method. The nanosilica $\left(\mathrm{SiO}_{2}\right)$ particles used are around $16 \mathrm{~nm}$ in diameter. The friction and wear test was conducted using the reciprocating wear testing machine. The tests were performed at rotary speed of $100 \mathrm{rpm}$ and $200 \mathrm{rpm}$ with load of $0.1 \mathrm{~kg}$ to $0.4 \mathrm{~kg}$ under $1 \mathrm{~N}$ interval. The effect of the $\mathrm{PU} /$ nano- $\mathrm{SiO}_{2}$ composite coating on friction and wear behavior of polypropylene substrate was investigated and compared. The worn surface of coating film layer after testing was investigated by using an optical microscope. The introduction of $\mathrm{PU} /$ nanosilica composite coating containing $3 \mathrm{wt} \%$ of nano- $\mathrm{SiO}_{2}$ content gives the lowest friction coefficient and wear rate to PP substrate. Both the friction and wear rate of PP substrate coated with $>3 \mathrm{wt} \%$ of nano-SiO${ }_{2}$ filled $\mathrm{PU}$ coating would increase with the increasing of applied load and sliding time.
\end{abstract}

\section{Introduction}

Polypropylene (PP) is an attractive engineering material due to its low cost, ease of processability, good mechanical properties, resistance to organic solvents, and favorable environmental aspects. However, the disadvantages of polypropylene are the lack of adhesion and poor scratch resistance $[1,2]$. Current technologies applied to improve scratch resistance of PP included coating, lamination, additives, and altering the nature of the PP resin. Incorporating metal-oxide nanoparticles such as nanoalumina and nanosilica into polymer coatings to enhance mechanical durability has been widely utilized in the current antiscratch and mar technologies [1]. Generally, hydrophobic surface type nanomaterials will be more attractive for polymer coating due to their unique properties such as self-cleaning, antisticking, water repellence and anticontamination $[3,4]$. From the recent research studies in nanoparticles field, hydrophobic nano- $\mathrm{SiO}_{2}$ particles have been widely introduced into coatings to improve the heat resistance, wear resistance, hardness, antisticking, and optical properties of the polymer materials $[1,2]$.

In polymeric coatings, the use of nanoparticles is more towards upgrading the level of resistance to wear and friction. The presence of nanoparticle in the surface layer of film enhances the scratch hardness and hence protects both the coating film and substrate against marring, cracking, wear, and mild abrasions [2]. Blees et al. [1] have studied the adhesion of the sol gel coating on polypropylene by using scratch test method that focuses on the effect of friction between indenter and coating on the critical load. The critical load (normal to the surface) showed a pronounced decrease of more than the order of magnitude with increasing of friction coefficient. Zhou et al. [2] have reported that the addition of nano- $\mathrm{SiO}_{2}$ can improve the hardness, abrasion resistance, scratch resistance, tensile strength, modulus, and weatherability of the polymer based coating lacquer. Despite using nano- $\mathrm{SiO}_{2}$ particles, the other nanoparticles such as $\mathrm{TiO}_{2}$, $\mathrm{SiC}, \mathrm{ZnO}, \mathrm{ZrO}_{2}$, and $\mathrm{Al}_{2} \mathrm{O}_{3}$ were also chosen to improve tribological properties [5-14]. Song et al. [5] have studied the tribological behaviours of the phenolic composite coating filled with modified nano- $\mathrm{TiO}_{2}$. The addition of small amounts of $\mathrm{TiO}_{2}$ or $\mathrm{TF}_{-} \mathrm{TiO}_{2}$ can improve the friction-reduction and antiwear abilities of phenolic coating, and $\mathrm{TF}-\mathrm{TiO}_{2}$ as a filler is superior to $\mathrm{TiO}_{2}$ in terms of ability to decrease the friction coefficient and wear rate of phenolic coating [6].

Recently, the gradual replacement of metal parts into polymeric components takes place in several industries 
especially in automotive and aerospace manufacture. Thus, the need for understanding the tribological behaviour of polymers substrate and polymer base coating materials becomes important. The polymer matrix composites (PMCs) are subjected to abrasive wear in many applications especially plowing effect from counterface hard asperities during coal handling, and the mining process has resulted in material removal and groves. Previous studies [15-18] have reported the effect of inorganic fillers to the friction and wear behavior of polyurethane coating; however, the tribological studies related to the performance of these polymers composite coatings onto various substrates are limited. Thus, this study was mainly focused on the effect of acrylic based polyurethane coating embedded with nanosilica to the wear and friction resistance of polypropylene substrate.

\section{Experimental}

2.1. Materials. In this work, acrylic based polyurethane, PU340, was supplied from Worldtex Specialty Chemical. PU 340 is a one-pack translucent solventborne polyurethane based on aliphatic urethane with approximately 30\% solid content (viscosity at $25^{\circ} \mathrm{C}$ : $80 \mathrm{MPa}$ ). Meanwhile, nanosilica, Aerosil R972, supplied by Degussa Huls, was used for the preparation of the nanocomposites. Aerosil R972 is one type of hydrophobic fumed silica treated with dimethyldichlorosilane (DDS) based on hydrophilic fumed silica. The average primary particle size of Aerosil R972 was $16 \mathrm{~nm}$ in average diameter with the specific surface area of $130 \mathrm{~m}^{2} / \mathrm{g}$. The mixture of toluene/isopropanol/ethyl acetate in a fixed volume fraction of $6: 3: 1$ was employed in the present work as a solvent. Polypropylene (PP) substrate with a size of $110 \mathrm{~mm}$ $\times 25 \mathrm{~mm} \times 1 \mathrm{~mm}$ was used as a substrate for PU/nanosilica composite coating. Various amounts of nanosilica powders ranging from 0 to $10 \mathrm{wt} \%$ were added to the polyurethane (PU) resin. The mixture was vigorously stirred using magnetic stirring at ambient temperature for at least 1 hour until clear dispersion and homogeneous mixture were obtained. To obtain the same coating thickness of around 3 micrometers for all samples, $1 \mathrm{~g}$ of the mixed suspensions was then directly coated on each PP substrate using Rod Mayer technique. The coating thickness is mainly determined by the withdrawal speed, by the solid content, and by the viscosity of the liquid [19]. The consistency of the coating thickness was controlled by monitoring the three factors above. Only the sample with the consistent thickness will be used for the further characterization study.

\subsection{Preparation of PU/Nanosilica Composite Coating on} PP Substrate. Nanosilica particles were directly embedded into the acrylic resin solution at $60^{\circ} \mathrm{C}$ under vigorous stirring for an hour. Polyurethane/nanosilica composite was deposited on polypropylene substrate using a Rod Mayer bar. The Rod Mayer technique was used to deposit the polyurethane/nanosilica composite material on the surface of the polyethylene substrate. Wire-wound rod 0.5 inch in diameter and 12 inches in length was used to spread the nanocomposite materials on the surface of the ceramic

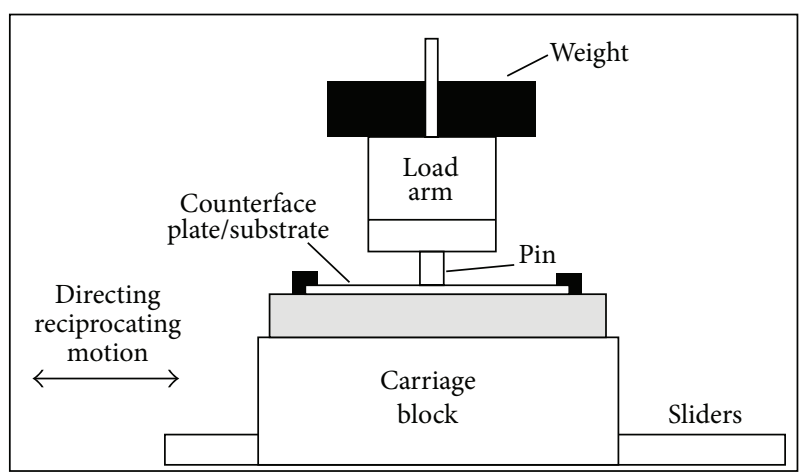

FIGURE 1: Schematic diagram of reciprocating wear machine.

substrate. The wire-wound rod used has wire of 20 mils. The PU/nanocomposite coating passes through the grooves between the wires and then levels off to a uniform thickness on the substrate. All the samples were cured in the laboratory with relative humidity of $40-60 \%$ and temperature of $25^{\circ} \mathrm{C}$. After solvent evaporation, a thin film around $3 \mu \mathrm{m}$ was obtained on the substrate.

2.3. Characterization. The nanocomposite coating thickness was measured by using optical microscope DM750P. The microstructure of PU coating and PU/nanosilica composite coatings was examined with a Field Emission Scanning Electron Microscope (FESEM, Hitachi Corporation, Japan) with accelerating voltage of $0.8 \mathrm{kV}$. For SEM study, a $1 \mathrm{~cm} \times$ $1 \mathrm{~cm}$ size piace was cut from the middle part of the sample. In order to increase the resolution for the SEM observation, the tested polymeric samples were plated with gold coating to render them electrically conductive. The friction and wear test was conducted under a dry and clean condition using Reciprocating Wear Testing Machine (BICERI). This apparatus consists of a stationary pin sliding on a reciprocating plate with its axis perpendicular to the direction of motion as illustrated schematically in Figure 1. The sizes of samples used are $110 \mathrm{~mm} \times 25 \mathrm{~mm}$ with the thickness of $2 \mathrm{~mm}$. The sliding performs at a rotary speed of $100 \mathrm{rpm}$ and $200 \mathrm{rpm}$ with the load varying from $0.1 \mathrm{~kg}$ to $0.4 \mathrm{~kg}$. The reciprocal sliding tests were run at a sliding distance of $80 \mathrm{~mm} /$ revolution with an interval of $0.1 \mathrm{~kg}$ and duration time of 10 minutes. The worn surface after testing was then observed using light optical microscope. All the friction and wear tests were carried out at ambient temperature, $20^{\circ} \mathrm{C}$ to $25^{\circ} \mathrm{C}$, with the relative humidity of $60 \%$. A computer program periodically records the amount of linear wear, which is equal to the decrease in pin height plus the depth of the groove worn in the plate.

\section{Results and Discussion}

FESEM was used to investigate the dispersion of nano- $\mathrm{SiO}_{2}$ particle and surface morphological changes of the nano$\mathrm{SiO}_{2}$ filled PU coating. The FESEM micrograph in Figure 2 reveals the dispersion condition of $3 \mathrm{wt} \%$ and $7 \mathrm{wt} \%$ of nano$\mathrm{SiO}_{2}$ contents in polyurethane coating. From Figure 2(a), the dispersion of $3 \mathrm{wt} \%$ of nanosilica particles in PU matrix 


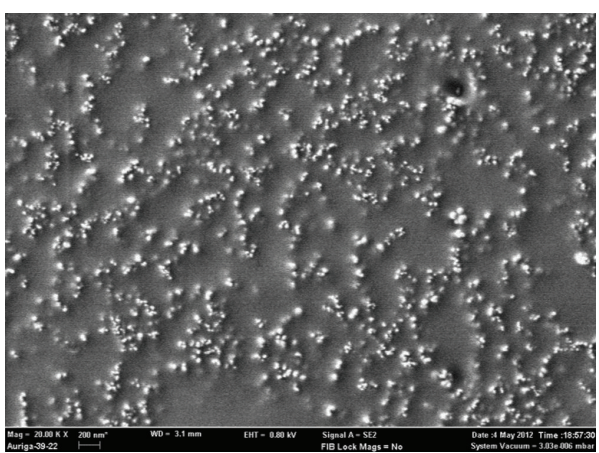

(a)

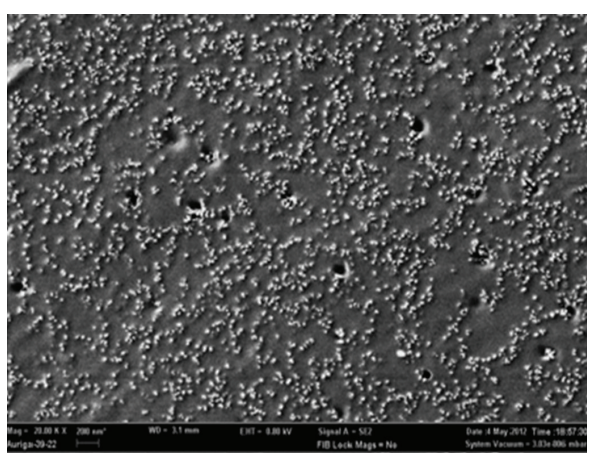

(b)

Figure 2: FESEM micrographs of PP substrate coated with (a) $3 \mathrm{wt} \%$ and (b) $7 \mathrm{wt} \%$ nano- $\mathrm{SiO}_{2}$ filled PU coating.

can be concluded to be well distributed with numerous clusters. However, there were higher agglomerates and aggregates found in polyurethane filled with $7 \mathrm{wt} \%$ of nano- $\mathrm{SiO}_{2}$ (Figure 2(b)). This microstructure had caused the increase of surface roughness for polyurethane films containing $7 \mathrm{wt} \%$ of nano- $\mathrm{SiO}_{2}$ content. The strong tendency of nano- $\mathrm{SiO}_{2}$ to agglomerate has caused difficulty to achieve homogenous dispersion in $\mathrm{PU} /$ nano- $\mathrm{SiO}_{2}$ composite coating especially filled with high content of nano- $\mathrm{SiO}_{2}$ particles. It was also found that there were some cavities or pores on the surfaces of $\mathrm{PU} /$ nano- $\mathrm{SiO}_{2}$ composite coating containing $7 \mathrm{wt} \%$ of nano- $\mathrm{SiO}_{2}$ that might be caused by the trapped air bubbles generated during the mixing and stirring process [6-11]. According to Kansy et al. [20], nanoparticles dispersion and surface roughness have considerable impact on the friction and wear behaviors of the nanocomposite coating. Higher roughness increases the asperities slope angle which in turn increases friction coefficient [21].

Figure 3 illustrates that the neat polypropylene achieves the highest friction coefficient with a value of 0.6 under $0.2 \mathrm{~kg}$ load. When neat polyurethane coating was introduced to PP substrate, it shows that there was a slight decrease in the coefficient of friction. The introduction of $3 \mathrm{wt} \%$ of nano- $\mathrm{SiO}_{2}$ into the $\mathrm{PU}$ coating layer has successfully reduced the friction coefficient of the nanocomposite coated PP from 0.56 to 0.30 . This might be due to the thin layer of $\mathrm{PU} /$ nano- $\mathrm{SiO}_{2}$ coating with low amount of nanomaterials which has provided a form of self-lubrication during sliding. The same observation was found in the research on titaniumcontaining amorphous hydrocarbon coatings [22, 23] and titanium carbide amorphous composite coating [24]. However, there was a sharp increase of friction coefficient of PP coated with $\mathrm{PU} /$ nano- $\mathrm{SiO}_{2}$ composite film when $7 \mathrm{wt} \%$ and $10 \mathrm{wt} \%$ nano- $\mathrm{SiO}_{2}$ particles were introduced to the composite. This may be closely related to the amount and distribution state of nanosilica particulates on coating surfaces, that is, the coating surface roughness. The polyurethane nanocomposite coatings with lower content of nanosilica may have smaller surface roughness thus lower friction coefficient, and for polyurethane nanocomposite coating with higher content of nanosilica, they may have larger surface roughness which leads to higher coefficient of friction. This is possibly due to

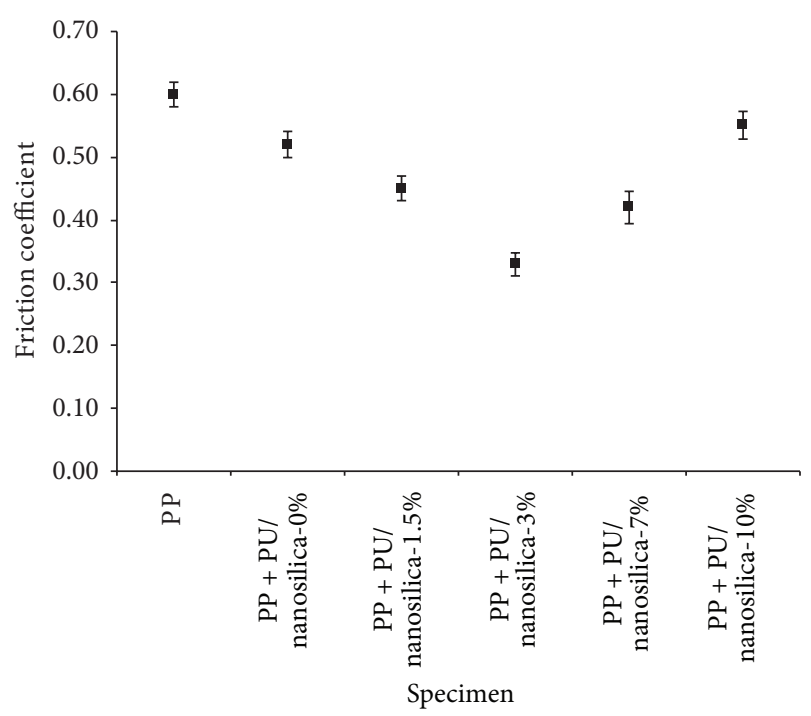

FIgUrE 3: The friction coefficient of $\mathrm{PU} /$ nano- $\mathrm{SiO}_{2}$ composite coated PP substrates under load of $0.2 \mathrm{~kg}$ with a speed of $100 \mathrm{rpm}$ in 10 min sliding time.

the different extent of abrasion action of nanosilica aggregates [22]. Hence, it can be concluded that the addition of small amounts of nano- $\mathrm{SiO}_{2}$ content can exhibit the improvement of friction coefficient of the polyurethane coated PP matrix.

Figure 4 shows the effect of applied load on the friction coefficient of nano- $\mathrm{SiO}_{2}$ filled $\mathrm{PU}$ coating under the speed of $100 \mathrm{rpm}$ in $10 \mathrm{~min}$ sliding time. It can be seen that PP, PP coated with a neat PU coating, and PP coated with PU filled with high amount of nano- $\mathrm{SiO}_{2}$ would increase with increasing applied load from $0.1 \mathrm{~kg}$ to $0.4 \mathrm{~kg}$. However, the friction coefficient of PP coated with $3 \mathrm{wt} \%$ of nano- $\mathrm{SiO}_{2}$ filled PU coating dropped when applied load increases from $0.1 \mathrm{~kg}$ to $0.2 \mathrm{~kg}$. This might be with the incorporation of small amounts of nanosilica; the effect of load on friction coefficient was caused by the elastic deformation of surface asperities under relatively lower load and the plastic deformation under relatively higher load $[25,26]$. At low load of $0.1 \mathrm{~kg}$ to $0.2 \mathrm{~kg}$, the particle-shaped or flaky debris on the surface of PP coated with $\mathrm{PU} /$ nano- $\mathrm{SiO}_{2}-3 \%$ composite would be crashed, staved, 


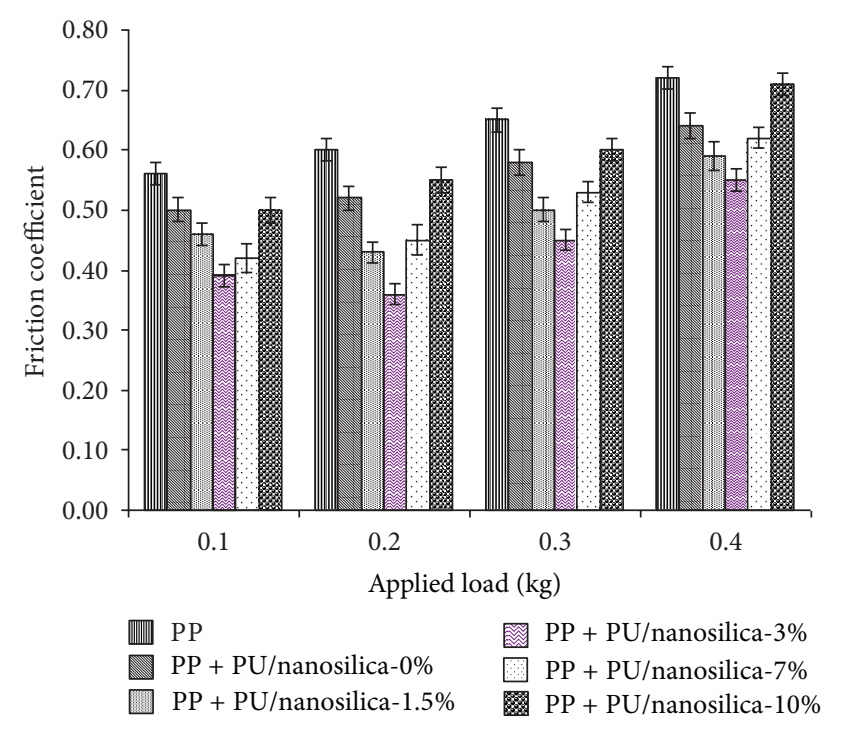

FIgURE 4: Effect of applied load on the friction coefficient of $\mathrm{PU} /$ nano- $\mathrm{SiO}_{2}$ composite coated PP under speed of $100 \mathrm{rpm}$.

or sheared into thinner flakes or small particles accordingly, thus reducing the surface roughness [27]. The newly formed debris would become more integrated, and concurrently, the film on the worn surface would be thinner. Consequently, the more integrated smaller debris but the thinner film on the worn surface would bring smaller friction coefficient due to the decrease in the degree of the two-body abrasive wear [28]. Therefore, the minimal friction coefficient was observed on PP coated with PU containing $3 \mathrm{wt} \%$ of nano- $\mathrm{SiO}_{2}$ particles under the applied load of $0.2 \mathrm{~kg}$. At higher loads, the plastic deformation occurs at the asperities in contact. Increasing applied load on nanocomposite layer with $3 \mathrm{wt} \%$ of nano$\mathrm{SiO}_{2}$ content would result in more nano- $\mathrm{SiO}_{2}$ dropping out from the polyurethane matrix during the friction process, which led to severe abrasive wear and resulted in a higher friction coefficient. With the high amount of $>3 \mathrm{wt} \%$ of nano$\mathrm{SiO}_{2}$ in $\mathrm{PU}$ coating, the friction coefficient increased with the increasing of applyied load due to the combination of both high amounts of nanosilica aggregates, and applied load would lead to severe plastic deformation of polyurethane coating, owing to mechanical incompatibility between the coating and substrate.

Since $3 \mathrm{wt} \%$ of nano- $\mathrm{SiO}_{2}$ filled PU composite coated on PP substrates shows the lowest friction coefficient, hence it appears as the optimal nanosilica content in PU. This proportion was further investigated for the effect in terms of applied load and speed on the friction behavior. Figure 5 illustrates the friction coefficient of PP coated with $3 \mathrm{wt} \%$ of nano- $\mathrm{SiO}_{2}$ filled $\mathrm{PU}$ under sliding speeds of $100 \mathrm{rpm}$ and $200 \mathrm{rpm}$ at different applied loads. The friction coefficient of all composite coated samples increases as sliding speed goes up from $100 \mathrm{rpm}$ to $200 \mathrm{rpm}$. The increase of friction coefficient with sliding speed is closely related to the frictioninduced heat. At higher speed, the friction-induced heat will pay a significant role at the frictional interface sliding compared to that at lower speed. This accelerated the degradation

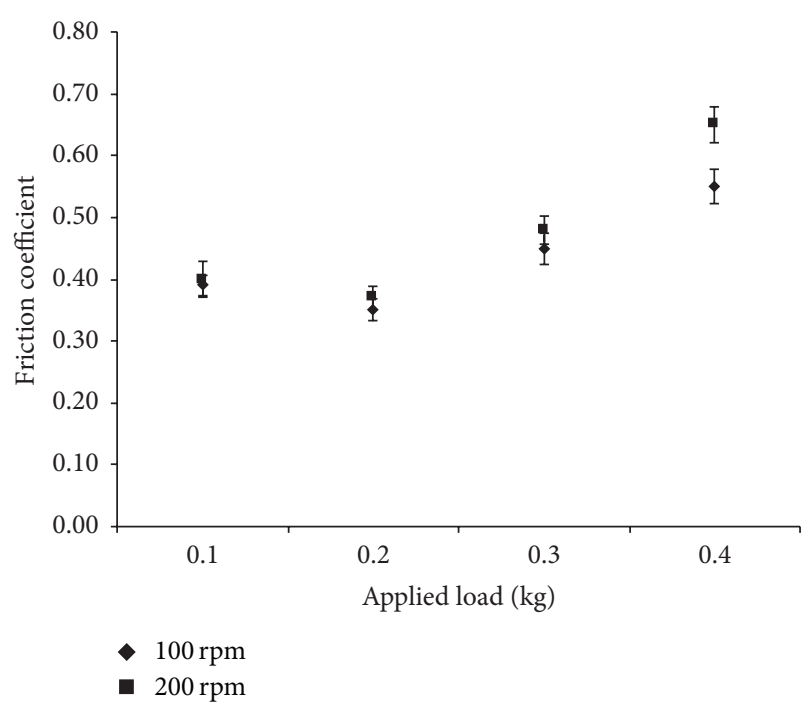

Figure 5: Effect of speed rate on friction coefficient of $3 \mathrm{wt} \%$ nano$\mathrm{SiO}_{2}$ filled PU coated PP substrate with different applied loads.

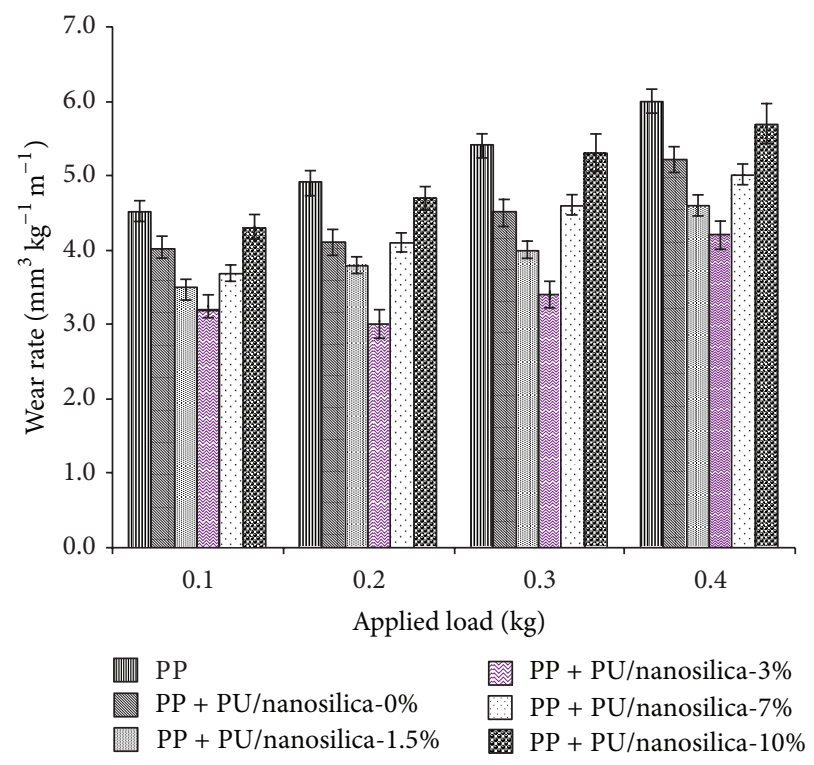

FIGURE 6: Effect of applied load on the wear rate of various compositions of $\mathrm{PU} /$ nano- $\mathrm{SiO}_{2}$ composite coated $\mathrm{PP}$ under speed of $100 \mathrm{rpm}$.

and decomposition of the polyurethane resin matrix and nanosilica, thus causing the increase of friction coefficient of the composite, and substrates became more severe at high sliding speed [29].

The effect of applied load on the wear rate of various compositions of $\mathrm{PU} /$ nano- $\mathrm{SiO}_{2}$ composite coated $\mathrm{PP}$ substrate under speed of $100 \mathrm{rpm}$ and 10 min sliding time is shown in Figure 6. The neat PP without composite coating layer shows the highest wear rate throughout the applied load ranges. The wear rate of PP substrate decreases significantly with the introduction of neat PU coating and PU/nanosilica composite coating modified with small amount of nano- $\mathrm{SiO}_{2}$ 


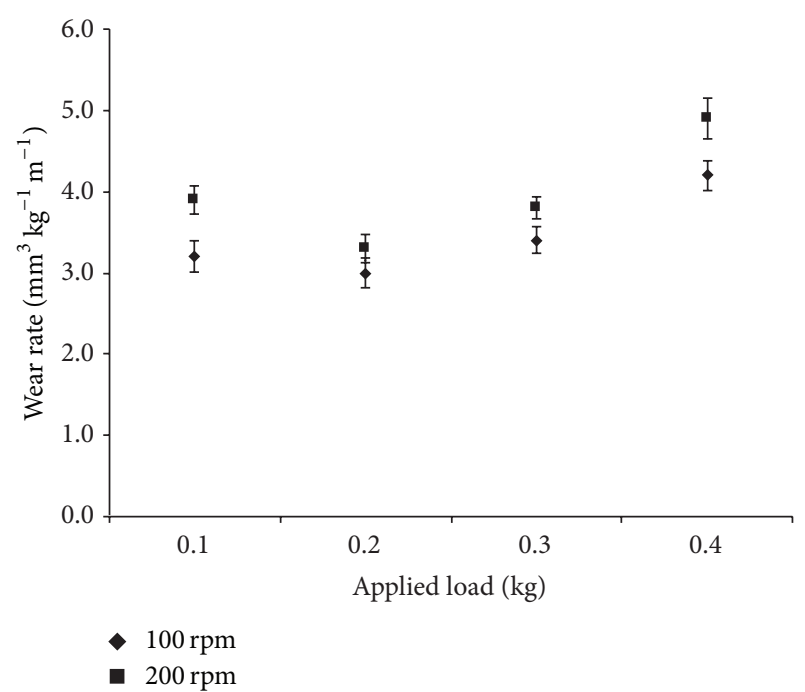

FIGURE 7: Effect of speed rate on the wear rate of $3 \mathrm{wt} \%$ nano- $\mathrm{SiO}_{2}$ filled PU coated PP substrate with different applied load.

particles. However, with addition of $>3 \mathrm{wt} \%$ of nano- $\mathrm{SiO}_{2}$ to the PU coating layer would increase the wear rate of the samples significantly. Hence, it can be concluded that the addition of small amounts of nano- $\mathrm{SiO}_{2}$ content at $3 \mathrm{wt} \%$ would lead to the improvement of wear rate of polyurethane coated PP substrate.

Same as the effect of friction coefficient, $3 \mathrm{wt} \%$ of nano$\mathrm{SiO}_{2}$ filled PU coating provides the lowest wear rate to PP substrate for all the applied loads from $0.1 \mathrm{~kg}$ to $0.4 \mathrm{~kg}$. The wear rate increases with the increasing of applied load for uncoated PP and PP coated with PU containing high amount of nano- $\mathrm{SiO}_{2}$ fillers (e.g., 7-10 wt\%). The increase in wear rate as a result of increasing load may be due to the failure of the coatings to protect the surface of the substrate as high applied load can lead to severe plastic deformation of the polyurethane coating. The plastic deformation is due to the mechanical incompatibility between the polyurethane coating and the substrate under high applied load. Higher amount of nano- $\mathrm{SiO}_{2}$ fillers also means a more severe aggregation of the fillers, thereby hindering the friction-reducing behavior of the filled composite coating, due to the abrasion action of the filler aggregates $[2,30,31]$. On the other hand, small amount of nano- $\mathrm{SiO}_{2}$ filler aggregates on composite coating surfaces may function to resist abrasion by the counterface asperities, thereby resulting in improved wear resistance of the composite coating $[2,30]$.

Figure 7 illustrates that the wear rate of $3 \mathrm{wt} \%$ nano- $\mathrm{SiO}_{2}$ filled PU coated PP substrate increases with the rising of applied loads of $>0.2 \mathrm{~kg}$ for both sliding speeds of $100 \mathrm{rpm}$ and $200 \mathrm{rpm}$. This indicates that the addition of nanosilica has helped in improving the ability of carrying loads in the polyurethane coating. The better antiwear behavior of nano- $\mathrm{SiO}_{2}$ coating under different applied loads mainly dominated by the elastic deformation of surface asperities under relatively lower load and plastic deformation under relatively higher load as has been described before $[25,30]$.
Hence, it can be concluded that the optimal amount of nano- $\mathrm{SiO}_{2}$ at $3 \mathrm{wt} \%$ filler aggregates on composite coating surfaces may function to resist abrasion by the counterface asperities, thereby resulting in improved wear resistance of the composite coating.

Figure 8 shows the optical micrographs of the worn surface of $\mathrm{PU} /$ nano- $\mathrm{SiO}_{2}$ composite coated PP substrate with various content of nano- $\mathrm{SiO}_{2}$ tested under the applied load of $0.2 \mathrm{~kg}$ and a speed of $100 \mathrm{rpm}$. The worn surface after wear test for PP coated with a neat PU coating shows signs of adhesion and abrasive wear (Figure 8(a)). The surface was very rough, displaying plucked and ploughed marks indicative of adhesive wear and ploughing. This might be due to fatigue-delamination generated under repeated loading during sliding [32]. Fatigue wear has been regarded as a main mechanism responsible for the sliding of the unfilled PU coating against a hard counterpart.

With the introduction of $3 \mathrm{wt} \%$ of nano- $\mathrm{SiO}_{2}$ contents in the PU coating layer, it can be seen that the worn surface of the nanocomposite coated PP substrate was smooth and showed only fine scratches as shown in Figure 8(b). It can be inferred that a polymer film layer can be transferred to the steel counterpart, and this results in a new counter surface producing primarily an adhesive wear mechanism. For polymer coating sliding surface, this mechanism is less harmful if compared to abrasive wear as this mechanism will result in a lower coefficient of friction and wear rate. This smooth, uniform, and compact worn surface leads to the good influence in increasing the wear resistance of $\mathrm{PU} /$ nano- $\mathrm{SiO}_{2}$ coating layer. This is proven from the previous friction and wear behaviors study. However, the worn surface appeared with severe plastic deformation and microcracking as the nano- $\mathrm{SiO}_{2}$ content in $\mathrm{PU} /$ nano- $\mathrm{SiO}_{2}$ composite was increased to $7 \mathrm{wt} \%$ (Figure 8(c)).

The worn surfaces of PP substrate coated with $3 \mathrm{wt} \%$ nano- $\mathrm{SiO}_{2}$ filled $\mathrm{PU}$ coating under different applied loads are shown in Figures 9(a)-9(c). Figure 9(a) shows that the worn surface of the coating was smooth under $0.1 \mathrm{~kg}$ load with speed of $100 \mathrm{rpm}$. When the applied load was increased to $0.2 \mathrm{~kg}$, there are some adhesion marks and cracks on the worn surfaces as shown in Figure 9(b). With further increase of applied load, there are some large amounts of cracks or flaky debris in the worn surface that would be crushed or sheared into smaller particles or thinner flakes and act as lubricants (Figure 9(c)). At the same time, the newly formed debris would come into being a more integrated layer on the worn surface and reduced the "direct contact" between the fabric composite and the counterpart.

The effect of speed on the worn surface of $3 \mathrm{wt} \%$ nano$\mathrm{SiO}_{2}$ filled PU coated PP substrate is shown in Figure 10. Mild wear occurred on the worn surface of the sample tested with the speed of $100 \mathrm{rpm}$ (Figure 10(a)). In Figure 10(b), the wear became severe under speed $200 \mathrm{rpm}$ indicating that the serious fatigue wear is the main wear mechanism of the filled PU coating when sliding under higher speed. It can be inferred that large area of frictional surface of the filled PU coating would flake away if the speed increases further and the coating would be seriously damaged. 


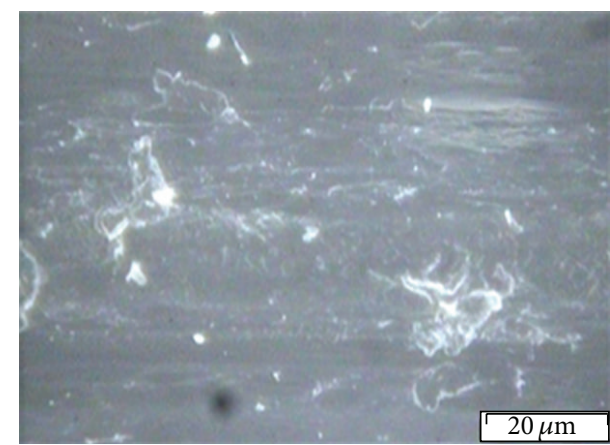

(a)

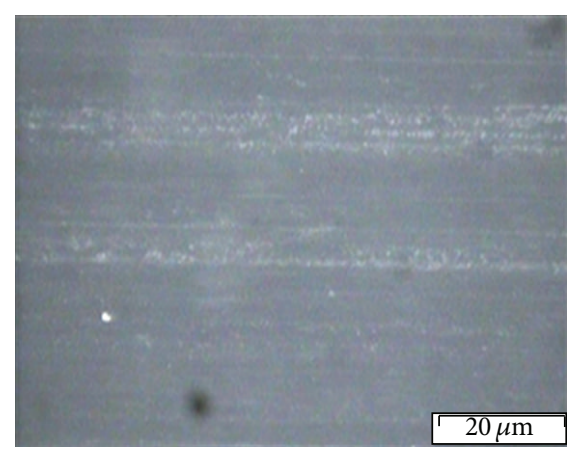

(b)

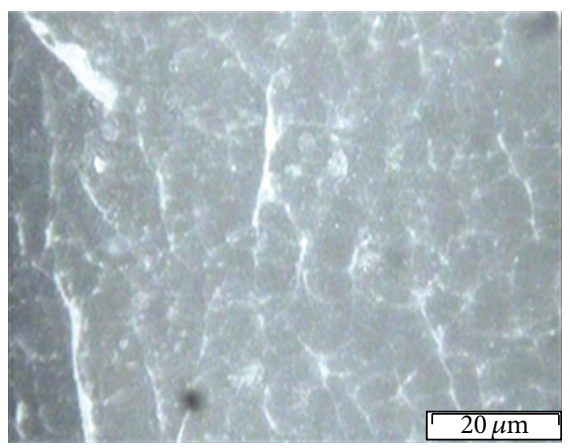

(c)

FIGURE 8: Optical micrographs of the worn surface of $\mathrm{PU} /$ nano- $\mathrm{SiO}_{2}$ composite coated $\mathrm{PP}$ with various content of nano-SiO${ }_{2}$ (a) 0 wt $\%$, (b) $3 \mathrm{wt} \%$, and (c) $7 \mathrm{wt} \%(0.2 \mathrm{~kg}, 100 \mathrm{rpm}, 10 \mathrm{~min})$.

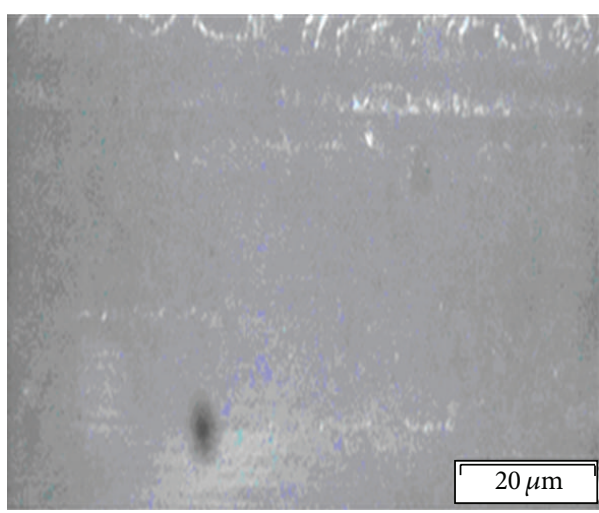

(a)

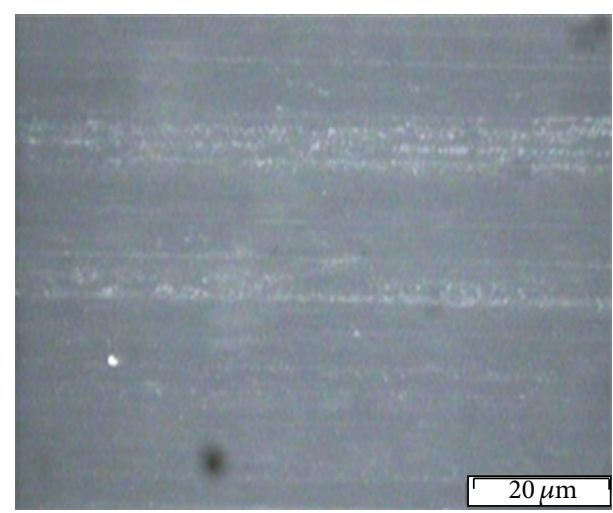

(b)

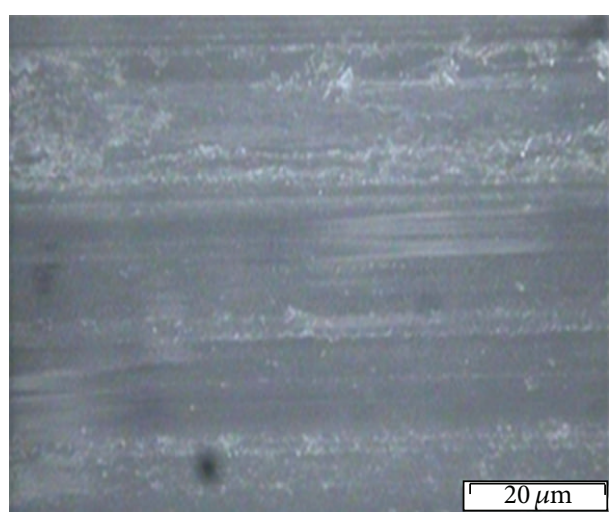

(c)

FIGURE 9: Optical micrographs of the worn surfaces of PP coated with 3 wt\% nanosilica filled PU coating under different applied loads (a) $0.1 \mathrm{~kg}$, (b) $0.2 \mathrm{~kg}$, and (c) $0.4 \mathrm{~kg}(100 \mathrm{rpm}, 10 \mathrm{~min})$. 


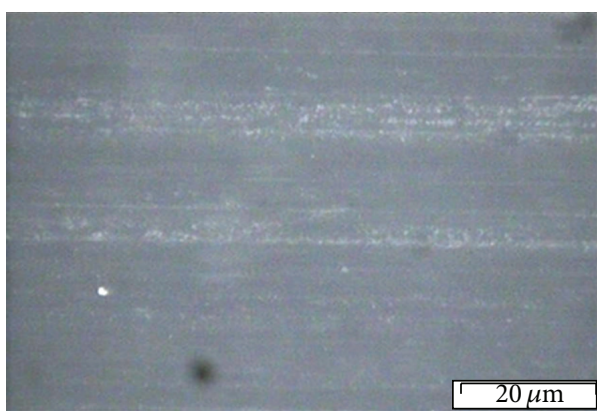

(a)

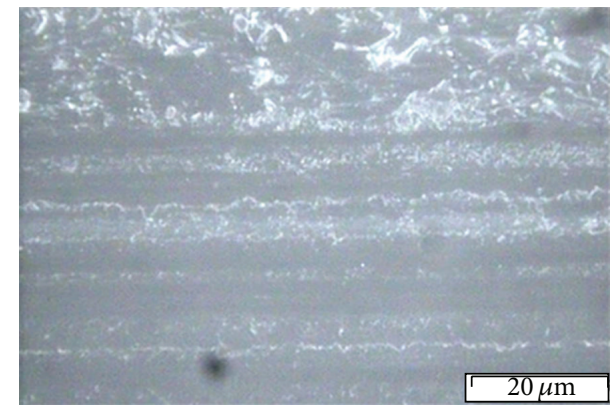

(b)

FIGURE 10: Optical micrographs of the worn surfaces of $3 \mathrm{wt} \%$ nanosilica filled polyurethane coating under $0.2 \mathrm{~kg}$ load, with different speeds of (a) $100 \mathrm{rpm}$ and (b) $200 \mathrm{rpm}(10 \mathrm{~min})$.

\section{Conclusions}

$\mathrm{PU} /$ nano-SiO2 composite coating without agglomeration was successfully prepared by using a magnetic stirring technique. Introduction of small quantities of nano-SiO2 into PU coating would resist the abrasion by counterface asperities and hence can improve the wear resistance of composite coating. The friction and wear behavior of PU/nano-SiO2 composite coating was closely related to the sliding condition, such as sliding speed and applied load. The sliding speed and applied load have influenced the wear process and the worn surface. The low load and speed combination has made the matric tend to adhere to nanoparticles and give the lesser degree of debris formation. The wear resistance behavior of $\mathrm{PU} /$ nano-SiO 2 composite coating under different applied loads was mainly dominated by both the elastic and plastic deformation. In this study, $\mathrm{PU} /$ nano-SiO2 composite coating with $3 \mathrm{wt} \%$ of nano-SiO 2 content exhibits a strengthened filler-matrix bonding has successfully protected the polypropylene substrate against wearing and mild abrasions.

\section{Acknowledgments}

The authors would like to thank the financial support provided by UMRG RP011A-13AET, PG079-2012B, FP0302013A, and ER014-2012A.

\section{References}

[1] M. H. Blees, G. B. Winkelman, A. R. Balkenende, and J. M. J. Den Toonder, "Effect of friction on scratch adhesion testing: application to a sol-gel coating on polypropylene," Thin Solid Films, vol. 359, no. 1, pp. 1-13, 2000.

[2] S. Zhou, L. Wu, J. Sun, and W. Shen, "The change of the properties of acrylic-based polyurethane via addition of nanosilica," Progress in Organic Coatings, vol. 45, no. 1, pp. 33-42, 2002.

[3] H.-J. Song, Z.-Z. Zhang, and X.-H. Men, "Superhydrophobic PEEK/PTFE composite coating," Applied Physics A, vol. 91, no. 1, pp. 73-76, 2008.

[4] J. B. Bharathibai and D. Kumar, "Fabrication of superhydrophobic nanocomposite coatings using polytetrafluoroethylene and silica nanoparticles," ISRN Nanotechnology, vol. 2011, Article ID 10.5402/2011/803910, 6 pages, 2011.

[5] H.-J. Song, Z.-Z. Zhang, and X.-H. Men, "Surface-modified carbon nanotubes and the effect of their addition on the tribological behavior of a polyurethane coating," European Polymer Journal, vol. 43, no. 10, pp. 4092-4102, 2007.

[6] D. Lingaraju, K. Ramji, M. P. Devi, and U. R. Lakshmi, "Mechanical and tribological studies of polymer hybrid nanocomposites with nano reinforcements," Bulletin of Materials Science, vol. 34, no. 4, pp. 705-712, 2011

[7] Y. C. Ching, Y. C. Ching, and I. I. Yaacob, "Weathering effect on virgin PE \& PE coated with polyamide/nanosilica composite coating," Journal of Computational and Theoretical Nanoscience, vol. 9, no. 9, pp. 1161-1164, 2012.

[8] Y. C. Ching, Y. C. Ching, and I. Yaacob, "Effect of polyurethane/ nanosilica composite coating on thermomechanical properties of polyethylene film," Materials Technology, vol. 27, no. 1, pp.113$115,2012$.

[9] Y. C. Ching, Y. C. Ching, and I. Yaacob, "Weathering resistance of solventborne polyurethane/nanosilica composite," Advanced Science Letters, vol. 27, pp. 165-169, 2012.

[10] Y. C. Ching and I. I. Yaacob, "Weathering effect on PE coated with thin layer of PU/nanosilica composite," Advanced Materials Research, vol. 181-182, pp. 697-701, 2011.

[11] Q.-H. Wang, X.-R. Zhang, and X.-Q. Pei, "Study on the friction and wear behavior of basalt fabric composites filled with graphite and nano-SiO${ }_{2}$," Materials and Design, vol. 31, no. 3, pp. 1403-1409, 2010.

[12] H.-J. Song, Z.-Z. Zhang, and X.-H. Men, “Tribological behavior of polyurethane-based composite coating reinforced with $\mathrm{TiO}_{2}$ nanotubes," European Polymer Journal, vol. 44, no. 4, pp. 10121022,2008

[13] Y. C. Ching and I. I. Yaacob, "Influence of nanosilica/polyurethane composite coating on IR effectiveness and visible light transmission properties of polyethylene," Advanced Materials Research, vol. 97-101, pp. 1669-1672, 2010.

[14] Y. C. Ching and I. I. Yaacob, "Influence of nano- $\mathrm{sio}_{2} /$ polyamide composites coating on thermic effect and optical properties of polyethylene film," International Journal of Modern Physics B, vol. 23, no. 6-7, pp. 1395-1400, 2009.

[15] Q.-H. Wang, X.-R. Zhang, and X.-Q. Pei, "Study on the friction and wear behavior of basalt fabric composites filled with graphite and nano-SiO${ }_{2}$," Materials and Design, vol. 31, no. 3, pp. 1403-1409, 2010. 
[16] F. Bauer, R. Flyunt, K. Czihal et al., "UV curing and matting of acrylate coatings reinforced by nano-silica and microcorundum particles," Progress in Organic Coatings, vol. 60, no. 2, pp. 121-126, 2007.

[17] F. Dolatzadeh, S. Moradian, and M. M. Jalili, "Effect of nanosilica on moisture absorption of polyurethane clear coats as studied by EIS and gravimetric methods," Progress in Color Colorants Coating, vol. 3, pp. 92-100, 2010.

[18] X. Gao, Y. Zhu, X. Zhao et al., "Synthesis and characterization of polyurethane $/ \mathrm{SiO}_{2}$ nanocomposites," Applied Surface Science, vol. 257, no. 10, pp. 4719-4724, 2011.

[19] S. K. Dhoke, N. Rajgopalan, and A. S. Khanna, "Effect of nanoalumina on the electrochemical and mechanical properties of waterborne polyurethane composite coatings," Journal of Nanoparticles, vol. 2013, Article ID 527432, 11 pages, 2013.

[20] J. Kansy, G. Consolati, and C. Dauwe, "Positronium trapping in free volume of polymers," Radiation Physics and Chemistry, vol. 58, no. 5-6, pp. 427-431, 2000.

[21] S. J. Bull, P. R. Chalker, C. Johnston, and V. Moore, "The effect of roughness on the friction and wear of diamond thin films," Surface and Coatings Technology, vol. 68-69, pp. 603-610, 1994.

[22] Y. Kang, X. Chen, S. Song, L. Yu, and P. Zhang, "Friction and wear behavior of nanosilica-filled epoxy resin composite coatings," Applied Surface Science, vol. 258, no. 17, pp. 63846390, 2012.

[23] M. M. Nikje, M. R. Khanmohammadi, and A. B. Garmarudi, "Nanosilica reinforced epoxy floor coating composites: preparation and thermophysical characterization," Current Chemistry Letter, vol. 1, pp. 1-8, 2012.

[24] D. M. Cao, B. Feng, W. J. Meng, L. E. Rehn, P. M. Baldo, and M. M. Khonsari, "Friction and wear characteristics of ceramic nanocomposite coatings: titanium carbide/amorphous hydrocarbon," Applied Physics Letters, vol. 79, no. 3, pp. 329-331, 2001.

[25] M. Rostami, Z. Ranjbar, and M. Mohseni, "Investigating the interfacial interaction of different aminosilane treated nano silicas with a polyurethane coating," Applied Surface Science, vol. 257, no. 3, pp. 899-904, 2010.

[26] D. K. Chattopadhyay and K. V. S. N. Raju, "Structural engineering of polyurethane coatings for high performance applications," Progress in Polymer Science, vol. 32, no. 3, pp. 352-418, 2007.

[27] K. Friedrich, J. Flöck, K. Váradi, and Z. Néder, “Experimental and numerical evaluation of the mechanical properties of compacted wear debris layers formed between composite and steel surfaces in sliding contact," Wear, vol. 250-251, no. 2, pp. 1202-1212, 2001.

[28] G. Zhao, T. Wang, and Q. Wang, "Studies on wettability, mechanical and tribological properties of the polyurethane composites filled with talc," Applied Surface Science, vol. 258, no. 8, pp. 3557-3564, 2012.

[29] H.-J. Song, Z.-Z. Zhang, X.-H. Men, and Z.-Z. Luo, "A study of the tribological behavior of nano- $\mathrm{ZnO}$-filled polyurethane composite coatings," Wear, vol. 269, no. 1-2, pp. 79-85, 2010.

[30] M. M. A. Nikje, A. B. Garmarudia, and M. Haghshena, "Nanosilica reinforced epoxy floor coating composites: preparation and thermophysical characterization," Current Chemistry Letters, vol. 1, pp. 13-20, 2012.

[31] Y. C. Ching, C. Y. Chen, and I. I. Yaacob, "Mechanical properties changes of nanosilica filled solventborne polyamide binder after accelerated weathering exposure weathering," Advanced Science Letters, vol. 13, pp. 575-578, 2012.
[32] R. O. Ritchie, "Mechanisms of fatigue-crack propagation in ductile and brittle solids," International Journal of Fracture, vol. 100, no. 1, pp. 55-83, 1999. 

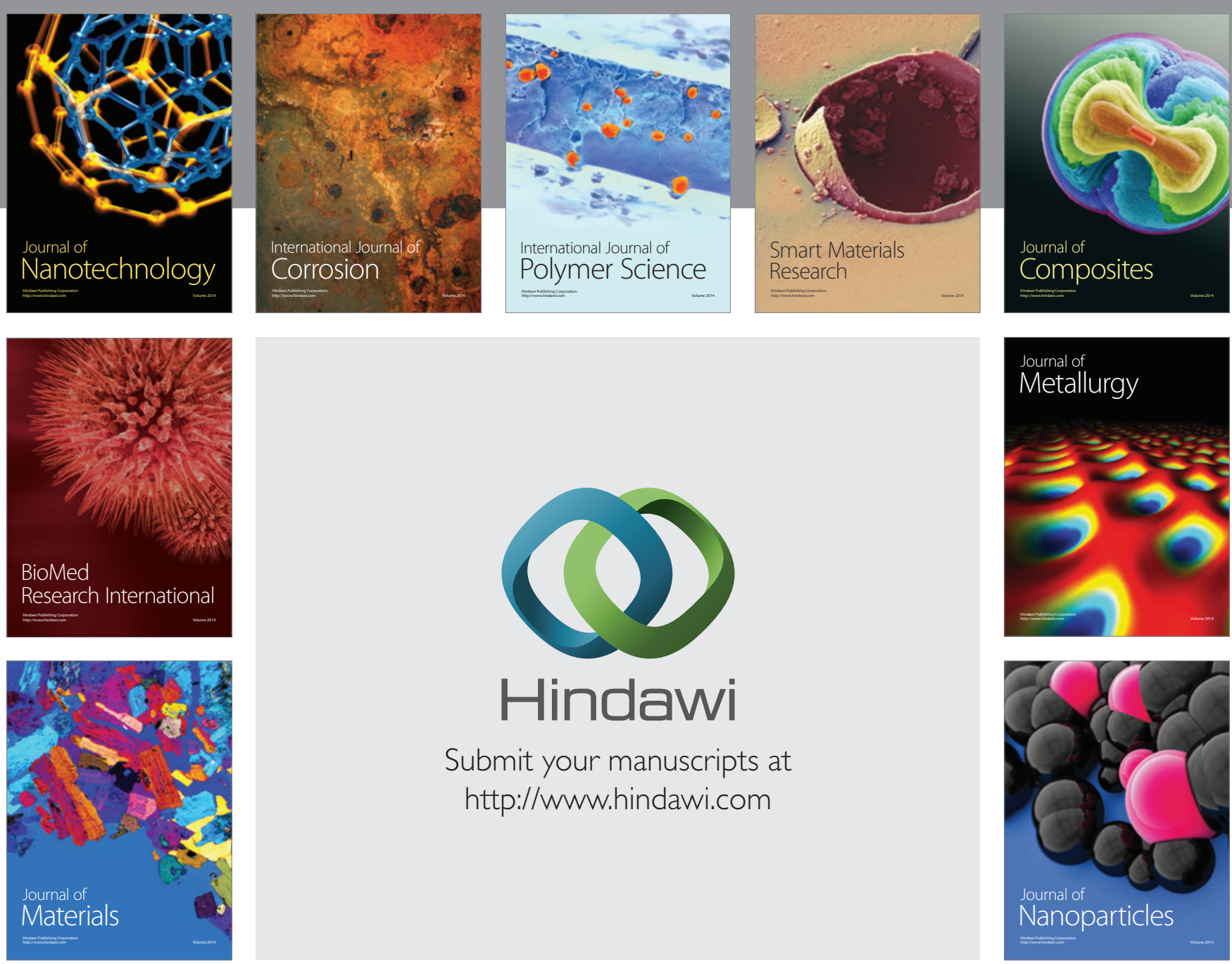

Submit your manuscripts at http://www.hindawi.com
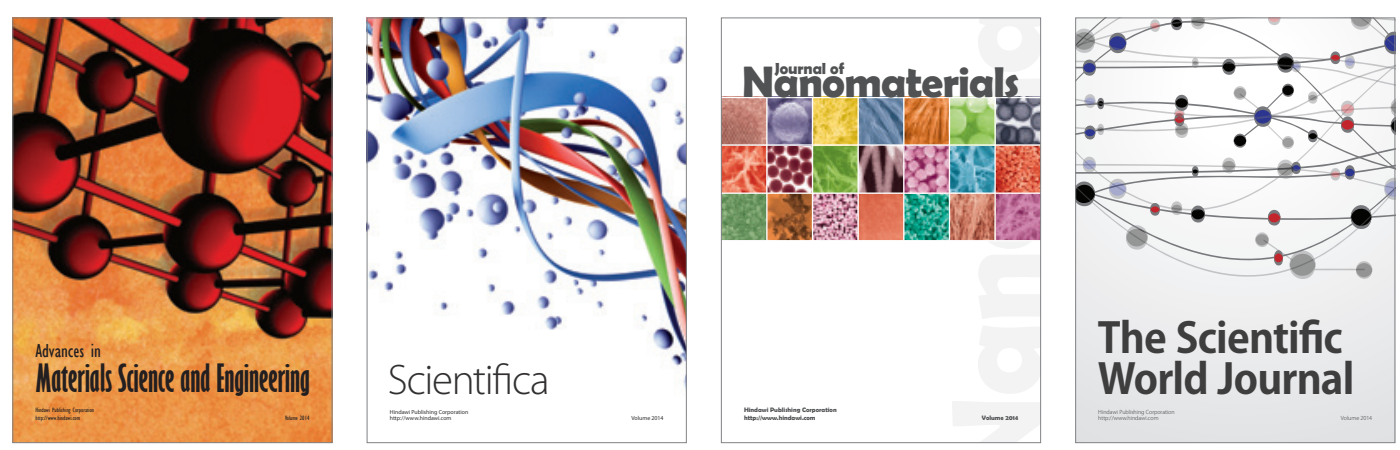

\section{The Scientific World Journal}
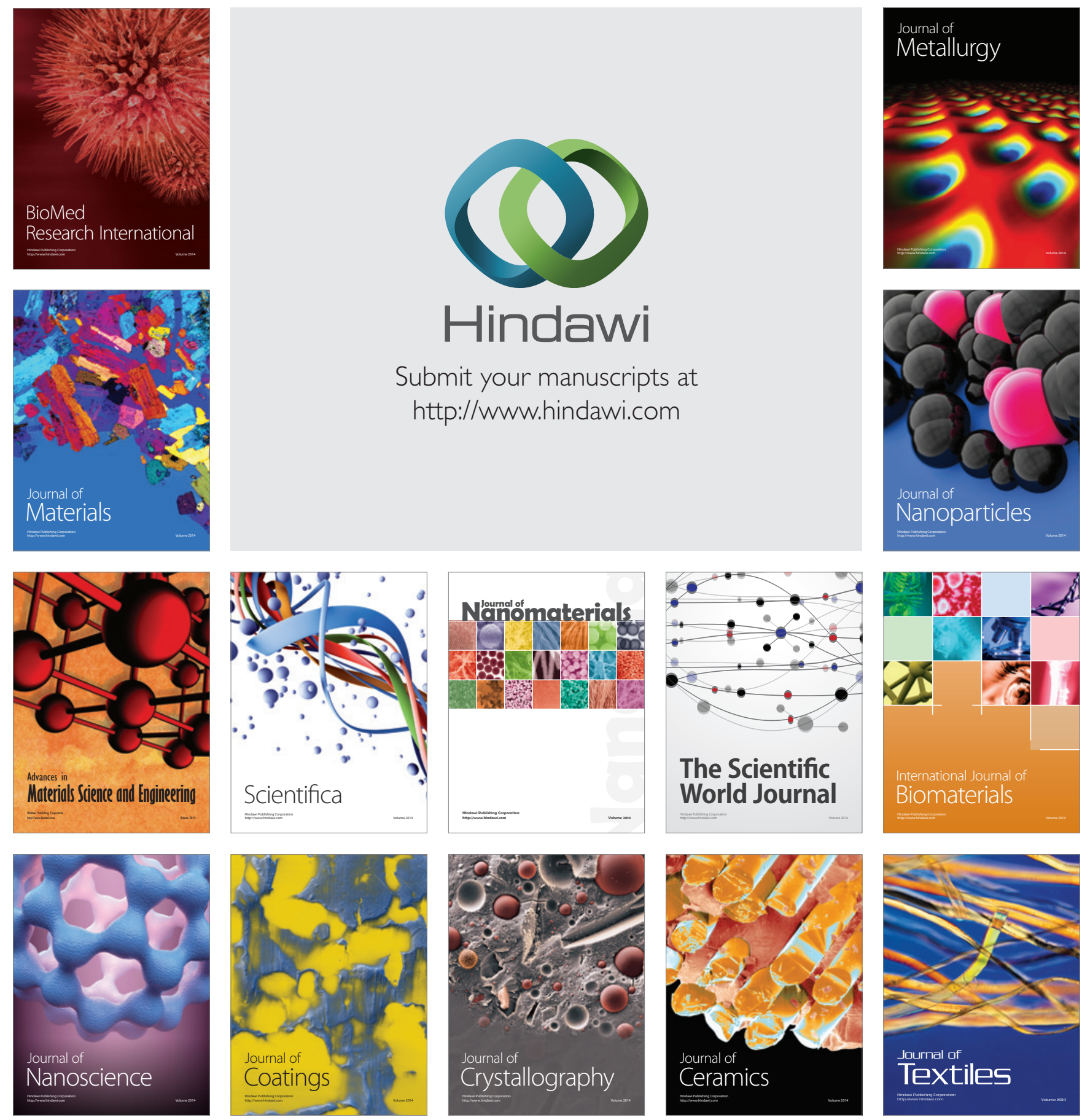